\title{
Correction to: Immunotherapy Advances in Urothelial Carcinoma
}

Rohit K. Jain ${ }^{1}$

Travis Snyders ${ }^{2}$

Lakshminarayanan Nandagopal ${ }^{3}$

Rohan Garje ${ }^{2}$

Yousef Zakharia

Shilpa Gupta ${ }^{4,5, *}$

\author{
Address \\ ${ }^{1}$ Moffitt Cancer Center, Tampa, FL, USA \\ ${ }^{2}$ University of Iowa, Iowa City, IA, USA \\ ${ }^{3}$ University of Alabama at Birmingham, Birmingham, AL, USA \\ ${ }^{4}$ Masonic Cancer Center, University of Minnesota, Minneapolis, MN, USA \\ ${ }^{*}, 5$ Hematology, Oncology and Transplantation, Department of Medicine, Univer- \\ sity of Minnesota, 14-100 Phillips Wangensteen Bldg, MMC 480, 516 Delaware St \\ SE, Minneapolis, MN, 55455, USA \\ Email: guptash@umn.edu
}

Published online: 23 May 2019

(C) Springer Science+Business Media, LLC, part of Springer Nature 2019

The online version of the original article can be found at https://doi.org/10.1007/s11864-018-0598-x

\section{Correction to: Curr Treat Options in Oncol (2018) 19:79 https://doi.org/10.1007/s11864-018-0598-x}

In the original version of this article, which published in Current Treatment Options in Oncology, Volume 19, Issue 12, December 2018, the surname of the third author was captured incorrectly. The name shown above is correct.

The publisher apologizes to Dr. Nandagopal as well as the readers for this error.

\section{Publisher's Note}

Springer Nature remains neutral with regard to jurisdictional claims in published maps and institutional affiliations. 